\title{
Douglas Kellner \& Jeff Share (2019). The Critical Media Literacy Guide: Engaging Media and Transforming Education. Leiden: Brill Sense, 125 pp., ISBN: 978-90- 04-40452-6.
}

Young people and children today tend to be especially immersed in and tethered to the digital ecology, but it is a reality for all that the lines between online and offline are blurry, and that new forms of media power based on algorithms, datafication, and platform capitalism rule. This is the case during leisure time and at home in participatory culture and networked publics. In education, digitalisation gives possibilities for ubiquitous and personalised learning inside and outside the classroom. To many, this is "the future of education" and the focus of progressive pedagogics, while others may see it as part of an ongoing corporate takeover of public education.

It can be reasonable here to talk of an underlying, hidden curriculum in this technological and cultural order. The opportunities are great, and the imaginaries and vision of its benefits for the future are many. At the same time, there are some obvious risks and downsides to this new form of qualification, socialisation, and subjectification of the (future) citizen, workforce, and prosumer. The commercialisation of everything is one, the unstoppable stream of stereotyped representations another. However, most concern seems to be projected on disinformation and misinformation, sensationalism, and rumours that circulate online, mixed with populism and tribal logics. This cocktail tends to feed distrust, in both institutions and groups beside one's own filter bubbles and identifications.

How can we best protect and empower "the media citizen of the future" and prepare them for this complex communication ecology? Two often heard suggestions are "digital competence" and "media and information literacy" (MIL), often focusing on rather individualised and instrumental "twenty-first century skills" while forgetting about systems of media power and politics. As a contrast to this, I suggest Douglas Kellner and Jeff Share's The critical media literacy guide: Engaging media and transforming education.

Kellner and Share want to "promote critical media literacy as a theoretical framework and practical pedagogy in order to enhance individual sovereignty vis-à-vis media culture, empowering people to critically read, write, and create a better world" (p. 14). For them, critical media literacy (CML) is "an important strategy for educators to strengthen civic engagement and reassert the promises of democracy with an informed and empowered citizenry" (p. 22). The theoretical base for their venture is a post-Marxist approach to media, socialisation, knowledge, and education. At the basis of this, we find critical theory and the Frankfurt School (critique of mass culture, dominant ideology, positivism, authoritarianism, etc.) in a dynamic combination with 
cultural studies (active audience, identity, etc.) and intersectionality (gender, race, ethnicity, etc.). Constructivism, politics of representation, and social and environmental justice also reside at the core of CML. This approach is also based on pedagogical principles from Dewey and Freire. John Dewey was the founder of progressive pedagogics and suggested that the teacher should create pedagogical situations based on problem solving, real life connections, experiments, and curiosity. Brazilian liberation (Marxian) philosopher Paulo Freire suggested experience and dialogue as key to the cultivation of critical consciousness (conscientização).

Accordingly, one of the goals of CML is to transform the ordinary classroom from a space of reproduction to a space of liberation, and in a deeply mediatised society this must be done in close connection to the students (digital) multiliteracies and popular culture knowhow. The goal is not only to train critical thinking as a skill, but to cultivate critical consciousness as a foundation to possible political and social actions, which eventually may contribute to positive changes in media, culture, and society.

CML pedagogy is based on distance to and dissociation from the familiar, and one still valid way to do this is deconstructions of "normality" and "objectivity" in dominating forms of media representation. Visuals, multimodal expressions, media production assignments, oral storytelling, and aural literacy are all parts of the CML toolbox, and any information and communication technology that is available in the schoolhouse or students' personal smartphones can be used for critical explorations of media and world.

This brief book (125 pp.) is said to address a wide audience - not least teachers. It can also be read as a pamphlet, as it offers an outline of a theory for pedagogical practice. It is in the two first chapters that Kellner and Share present their theoretical and political foundations, which they then link to practical examples from their own teaching practices or various American classrooms. The authors underline the importance (and challenge) of implementing CML in teacher education and argue that CML has a place and function in all school subjects, since it not only concerns "the media" but the creation of a more equal society and humanistic world.

Kellner and Share both reside in a west coast context (University of California, Los Angeles) and have, as left-wing liberals and radical academics, pedagogues, and activists, been central to American media literacy for a long time. Kellner has published books about media culture, but also on cultural studies, Baudrillard, postmodernism, and the Frankfurt School. Share is a radical pedagogue and has a parallel career as photographer. Their book is a refreshing break from dominant discourses on MIL and digital competence and it is notable that it was released around the same time British media literacy nestor David Buckingham published his Media education manifesto (see a review by Katrin Saks in this issue). Perhaps this signals a generational shift - or a transatlantic call out for the resurrection of Bildung and intellectual work in times when presentism and instrumentalism rage pedagogics, and thus also media literacy. This is a legacy for others to shoulder. It is 
confusing that the critical consciousness and critique of dominant media that Kellner and Share want to foster in the complexity of today's technological and political ecology could be used even from a right-wing position. However, there are some major differences, since what Kellner and Share offer is a media critique based on hope and creativity - not cynicism, hate, or contempt. They also position themselves as spokespersons for universal rights (the right to communicate, information rights, etc.), empathy, and solidarity combined with environmental and social justice, and personal responsibility and agency. To me, and many of us, this remains the most fruitful way forward.

Michael Forsman Södertörn UNIVERSITY, SWEDeN 